\title{
The association between dietary intakes and stone formation in patients with urinary stones in Shiraz
}

\author{
Hadi Bazyar ${ }^{1,2}$, Afsane Ahmadi*3, Ahmad Zare Javid ${ }^{4}$, Dariush Irani ${ }^{5}$, Mohsen Mohammadi Sartang ${ }^{6}$, \\ Mohammad Hossein Haghighizadeh ${ }^{7}$
}

Received: 20 Dec 2017

Published: 20 Feb 2019

\begin{abstract}
Background: Kidney stone is a common and costly disease, but it may be improved by a healthy diet. The aim of this study was to evaluate the association between dietary intake and stone formation in patients with urinary stones in Shiraz.

Methods: In this cross sectional study, 110 patients with kidney stone were selected from Faghihi hospital, Shiraz. Demographic information was collected, and anthropometric indices, disease-related variables, physical activity (using IPAQ), and dietary intake (using food frequency questionnaire, analyzed by Nut 4 software, to estimate micro and macro nutrients) were evaluated. Independent sample $t$ test and one-way ANOVA were used to compare the quantitative variables between the 2 groups and multi groups, respectively. Chi square test was also used to compare qualitative variables. The correlation between variables was determined using Pearson test.
\end{abstract}

Results: Out of 110 participants in this study, 37 (33.6\%) were female, with the mean BMI of $27.0 \pm 4.68 \mathrm{~kg} / \mathrm{m} 2$, and $73(66.4 \%)$ were male, with the mean BMI of $24.21 \pm 2.96 \mathrm{~kg} / \mathrm{m} 2$. The mean intake of calcium-containing foods ( $\mathrm{p}=0.02)$ and high-fructose beverages $(\mathrm{p}=0.03)$ was significantly greater in patients with calcium stones compared to those with uric acid stones. The mean intake of high-purine foods was significantly higher in patients with uric acid stones than in those with calcium stones ( $\mathrm{p}=0.007)$. The mean intake of vitamin $A(p=0.02)$, beta-carotene $(p=0.03)$, and fructose $(p=0.03)$ was significantly higher in patients with calcium stones than in those with uric acid stones, while caffeine intake was significantly higher in patients with uric acid than in those with calcium stones $(p=0.01)$. There was a significant correlation between consumption of high-oxalic beverages $(p=0.005$, correlation coefficient $=$ $0.26)$ and high-fructose $(p=0.048$, correlation coefficient $=0.18)$ with spontaneous stone expulsion.

Conclusion: There was a significant relationship between consuming vitamin A, beta-carotene, and foods containing calcium, purine, fructose, and oxalate and formation of kidney stones. Therefore, adopting a healthy diet and increasing physical activity may be effective in the treatment of kidney stones.

Keywords: Urinary stones, Nutritional factors, Nutrients, Obesity, Physical activity

Conflicts of Interest: None declared

Funding: Student Research Committee of Shiraz University of Medical Sciences.

\section{*This work has been published under CC BY-NC-SA 1.0 license.}

Copyright $₫$ Iran University of Medical Sciences

Cite this article as: Bazyar H, Ahmadi A, Zare Javid A, Irani D, Mohammadi Sartang M, Haghighizadeh MH. The association between dietary intakes and stone formation in patients with urinary stones in Shiraz. Med J Islam Repub Iran. 2019 (20 Feb);33:8. https://doi.org/10.47176/mjiri.33.8

\section{Introduction}

Kidney stone is a common and costly disease (1), which is formed by mineral density due to changes in urinary

Corresponding author:Dr Afsane Ahmadi, ahmadi.afsane@gmail.com

1. Student Research Committee, School of Nutrition and Food Sciences, Shiraz University of Medical Sciences, Shiraz, Iran

2. Student Research Committee, School of Allied Medical Sciences, Ahvaz Jundishapur University of Medical Sciences, Ahvaz, Iran

3. Research Center for Health Sciences, Department of Clinical Nutrition, School of Nutrition and Food Sciences, Shiraz University of Medical Sciences, Shiraz, Iran

4. Department of Nutrition, School of Allied Medical Sciences, Ahvaz Jundishapur University of Medical Sciences, Ahvaz, Iran

5. Department of Surgery, Shaheed Faghihi Hospital, Shiraz University of Medical Sciences, Shiraz, Iran

6. Nutrition Research Center, Shiraz University of Medical Sciences, Shiraz, Iran

7. Department of Biostatistics, School of Public Health, Ahvaz Jundishapur University of Medical Sciences, Ahvaz, Iran $\uparrow$ What is "already known” in this topic:

Prevalence of kidney stones, especially in developing countries, is increasing due to unhealthy lifestyle (reduced physical activity and increased obesity) and food regimen. This problem endangers public health and imposes great therapeutic costs on countries. To date, no cross sectional study has been conducted to investigate the relationship between dietary intake and stone formation in Shiraz, Iran.

\section{$\rightarrow$ What this article adds:}

The results of this study showed that the mean intake of calcium-containing foods was significantly higher in the group with calcium stones compared to the group with uric acid stones. However, high-purine foods were significantly more consumed in the group with uric acid stone compared to calcium stone group. However, the mean intake of vitamin D and calcium were significantly less than dietary reference intakes (DRI) in both groups. DRI is a general term for a set of reference values used to plan and assess nutrient intakes of healthy participants 
environmental conditions (2). Low urine volume is the most important factor in stone formation; also, kidney stone is more prevalent in those with hypothyroidism, long-term immobility, and osteoporosis (3). There are 5 types of crystalline compounds for urinary stones, including calcium oxalate, calcium phosphate, bacteria-related stones (struvite), uric acid, and cysteine and a combination of 2 or more forms of stones (4). Calcium stones, mainly calcium oxalate, are involved in about $80 \%$ of kidney stones (5). The prevalence of kidney stone disease is 3\%$5 \%$ in females and $10 \%-15 \%$ in males (6). In Iran, the prevalence of kidney stone disease was reported to be 4.2 per 1000 (7). Kidney stone disease is 4 times more common in men than in women and is more common in people working in hot and low-mobile environments and in the summer. This ratio is also higher in obese and white people (8). Obesity and overweight are risk factors for stone formation (9). The role of nutrition in formation of kidney stones was identified in adult population (10). High-fiber and fruit diets may protect against the risk of stones (11). Increased consumption of magnesiumcontaining foods (almonds and bananas) may be associated with reduced risk of stone formation (12). Increased consumption of high-oxalate foods may significantly increase oxalate secretion, even in healthy individuals, without disturbing oxalate metabolism (13). Consumption of animal protein (like egg white) reduces urinary $\mathrm{pH}$ and increases urinary uric acid, which are harmful agents for the formation of calcium and uric acid stones. It was indicated that in men with calcium stones, the rate of stone recurrence is higher in those with a low calcium diet than in those with a low protein, low sodium, and normal calcium diet (14). Also, there is a risk of hospitalization for these individuals with an increase in meat consumption. Consumption of 100 grams of meat, compared to 50 grams, is associated with a $30 \%-50 \%$ increase in the risk of stone formation (15). Using a DASH diet (a diet containing high potassium fruits and vegetables), with a moderate amount of low-fat dairy and a low amount of animal protein, reduces the risk of kidney stones (16), which actually increases the amount of urinary secretion of citrate (17). Salt is another factor contributing to the formation of calcium stones, especially in people who have stoneforming kidneys. There is a relationship between stone formation and consumption of salty substances, such as pickled cucumber, canned food, sausages, and prepared foods (18). In general, it is suggested that diets rich in oxalate, protein, sodium, ascorbic acid, and purine increase the risk of formation of kidney stones and diets rich in water, potassium, and magnesium reduce the risk of stone formation (19). Drinking fluids, especially water, reduces the risk of stone formation in patients with kidney stones. In addition, sugar-free lemon juice is effective in reducing the risk of stone formation (20). Some studies found a strong correlation between high-fructose consumption and increased risk of formation of kidney stones (21).

Prevalence of kidney stones and food patterns in different regions is difference, and to date, no cross sectional study has been conducted in Shiraz to investigate the rela- tionship between dietary intakes and stone formation. Therefore, this study aimed to determine the association between dietary intake and stone formation in patients with urinary stones in Shiraz.

\section{Methods}

In this cross sectional study, 115 patients with kidney stones who referred to Faghihi hospital in Shiraz were selected using convenience sampling method in 20152016. An informed consent was obtained from the participants. The present study was approved by the Ethics Committee of Shiraz University of Medical Sciences (No. 9769). The participants aged 18-60 years, did not follow a particular diet, and did not have any underlying or related complications, such as inflammation, kidney or bladder infection. Of the participants, 5 were excluded from the study due to taking calcium, vitamin D and vitamin C supplements, and antacids. Some specific biochemical tests, ultrasounds, and the physician's approval were also collected. The type of stone was determined according to the morphological analysis by a microscope. The main stone was considered for each stone with $>50 \%$ composition compared to other stones. A 5-part questionnaire was used to collect data, which included demographic characteristics (age, sex, occupation, educational level, place of residence), anthropometric indices (height, weight, body mass index), information about the disease (stone type, number of stones, spontaneous expulsion, use of lithotripsy, surgery, family history of stones), physical activity questionnaire (IPAQ), and validated food frequency questionnaire (FFQ). The IPAQ contained 3 sections of questions as heavy activity (coefficient of 8), moderate activity (coefficient of 4), and walking (coefficient of 3.3), which were added up. The activities ranged from 0 to 600,600 to 3000 , and greater than $3000 \mathrm{~min} / \mathrm{w}$, which were considered as light, moderate, and heavy respectively. The person must work continuously for at least 10 minutes to consider the score. The validity and reliability of this questionnaire were confirmed, with Cronbach's alpha of $42 \%$ and $70 \%$ by retest method (22). The amount of consumable foods was reported as servings. Body weight was measured using Japanese body composition monitor digital scale, with a precision of $0.1 \mathrm{~kg}$, without shoes and with the least possible clothing. To measure height, the participant was asked to stand against the wall, and a tape meter was used with a precision of $0.5 \mathrm{~cm}$. The anthropometric indices were compared with CDC 2-20 standards. SPSS version 19 was used for data analysis. Independent $t$ test and one-way ANOVA were used to compare the quantitative variables between the 2 groups and multi groups, respectively. Comparison between qualitative variables was done using chi square test. Pearson test was used for correlation measurement. All data were expressed as mean \pm standard deviation, and $\mathrm{p}<0.05$ was considered as significant. The Nut 4 software was used to estimate the intakes of energy, carbohydrate, protein, fat, and micronutrients. For certain nutrients considerably related to the stone, the intakes were compared with dietary reference intakes (DRI) by one-sample $\mathrm{t}$ test. The sample size $(n=100)$ in this study was estimated using the Cochran 
formula, with $\alpha=0.0, \mathrm{p}=\mathrm{q}=0.5$, and $\mathrm{d}=0.1$ (23).

\section{Results}

Out of 110 participants in this study, 37 (33.6\%) were female, with the mean BMI of $27.0 \pm 4.68 \mathrm{~kg} / \mathrm{m}^{2}$, and 73 $(66.4 \%)$ were male, with the mean BMI of $24.21 \pm 2.96$ $\mathrm{kg} / \mathrm{m}^{2}$. Also, $75.7 \%$ of female and $74 \%$ of the male patients had calcium oxalate stones $(18.9 \%$ uric acid, $1.9 \%$ cystine stones). Also, 2 patients with cystine stones were excluded for better analysis (Table 1). The mean intake of calcium-containing foods was significantly higher in the group with calcium stones compared to the group with uric acid stones $(\mathrm{p}=0.02)$. High-purine foods were significantly more consumed in the group with uric acid stone compared to the group with calcium stone group $(p=0.007)$. The mean intake of high-fructose beverages in the group with uric acid stone was significantly lower than in the group with calcium oxalate stones $(\mathrm{p}=0.038)$. However, no significant difference was observed between the groups in the mean intake of other foods (Table 2). The mean intakes of vitamin A, beta-carotene, and fructose were significantly higher in patients with calcium oxalate stones than in patients with uric acid stones $(p<0.05)$. However, caffeine intake was higher in the group with uric acid stone than in the group with calcium oxalate stones $(\mathrm{p}=0.01)$. There was no significant difference in the intake of other nutrients between the 2 groups (Table 3). There was no significant difference between age $(p=0.83)$ and sex $(\mathrm{p}=0.61)$ and calcium oxalate and uric acid stones in the 2 groups. The intake of micronutrients mostly related to kidney stones, including sodium, potassium, phosphorus, vitamin D, calcium, B6, magnesium, and vitamin c, were compared with DRI in all participants. The mean intake of vitamin D and calcium were significantly less than DRI in both groups $(\mathrm{p}<0.05)$. However, the mean intake of sodium, vitamin B6, and vitamin $\mathrm{C}$ were significantly greater than DRI in both groups $(p<0.05)$. The intake of other micronutrients, such as potassium, phosphorus, and magnesium, were similar to DRI (Table 4). The results of Pearson correlation showed a significant correlation between high-oxalate beverages and spontaneous stone expulsion in 1 year $(\mathrm{p}=0.005, \mathrm{R}=0.26)$. Moreover, a significant correlation was found between high-fructose beverages and stone expulsion during 1 year $(\mathrm{p}=0.048$, $\mathrm{R}=0.18$ ); nonetheless, this relationship was not significant

Table 1. Demographic indices of participants based on sex

\begin{tabular}{|c|c|c|c|c|}
\hline \multicolumn{4}{|l|}{ Variable } & Male \\
\hline \multirow[t]{5}{*}{${ }^{\dagger} \mathrm{Job}$} & Unemp & & $0(0)$ & $29(39.7)$ \\
\hline & The w & & $0(0)$ & $23(31.5)$ \\
\hline & house & & $34(91.8)$ & $0(0)$ \\
\hline & Empl & & $3(8.1)$ & $21(28.8)$ \\
\hline & Tot & & $37(100)$ & $73(100)$ \\
\hline \multirow[t]{5}{*}{$\dagger$ Education } & Illiterate-el & ntary & $20(54.1)$ & $18(24.7)$ \\
\hline & Tip & & $8(21.6)$ & $18(24.7)$ \\
\hline & Secondar & 1001 & $5(13.5)$ & $18(24.7)$ \\
\hline & Acad & & $4(10.8)$ & $19(26)$ \\
\hline & Tot & & $37(100)$ & $73(100)$ \\
\hline \multirow[t]{3}{*}{$\dagger$ Habitation } & Villa & & $18(48.6)$ & $30(41.1)$ \\
\hline & Cit & & $19(51.4)$ & $43(58.9)$ \\
\hline & Tot & & $37(100)$ & $73(100)$ \\
\hline \multirow[t]{4}{*}{$\dagger$ Physical activity } & Lo & & $23(62.2)$ & $20(27.4)$ \\
\hline & Mode & & $7(18.9)$ & $21(28.8)$ \\
\hline & Hig & & $7(18.9)$ & $32(43.8)$ \\
\hline & Tot & & $37(100)$ & $73(100)$ \\
\hline \multirow[t]{4}{*}{$†$ †ype of urinary stones } & Calcium & late & $28(75.5)$ & $54(74)$ \\
\hline & Uric & & $7(18.9)$ & $19(26)$ \\
\hline & Sist & & $2(5.4)$ & $0(0)$ \\
\hline & Tot & & $37(100)$ & $73(100)$ \\
\hline${ }^{*}$ Height $(\mathrm{cm})$ & & & $154.97 \pm 6.82$ & $173.61 \pm 7.11$ \\
\hline *Weight $(\mathrm{kg})$ & & & $64.67 \pm 10.81$ & $73.13 \pm 10.77$ \\
\hline * BMI $(\mathrm{Kg} / \mathrm{m} 2)$ & & & $27 \pm 4.68$ & $24.21 \pm 2.96$ \\
\hline *Age (year) & & & $47.35 \pm 11.13$ & $42.46 \pm 12.02$ \\
\hline \multicolumn{5}{|c|}{$\begin{array}{l}\dagger . \text { The data are presented as "number (percent)." } \\
\text { *. The data are presented as "mean } \pm \text { SD". }\end{array}$} \\
\hline \multicolumn{5}{|c|}{ Table 2. Comparison of mean food intake per week based on type of urinary stone } \\
\hline \multirow[b]{2}{*}{ Foodstuff } & Stone type & Calcium oxalate & Uric acid & \multirow[t]{2}{*}{$\mathrm{p}$} \\
\hline & & & $\begin{array}{l}\text { (servings per week) } \\
\text { nean } \pm \mathrm{SD}\end{array}$ & \\
\hline Potassium-rich fruits & & $24.75 \pm 9.53$ & $21.81 \pm 9.53$ & 0.14 \\
\hline Calcium-rich foods & & $18.68 \pm 7.82$ & $14.88 \pm 5.11$ & $0.02^{*}$ \\
\hline High oxalate foods & & $9.64 \pm 7.42$ & $9.42 \pm 6.12$ & 0.88 \\
\hline Drinks with high oxalate & & $25.59 \pm 15.93$ & $25.09 \pm 12.42$ & 0.88 \\
\hline High-sodium foods & & $13.13 \pm 7.02$ & $13 \pm 4.58$ & 0.91 \\
\hline High-purine foods & & $11 \pm 4.59$ & $13.86 \pm 4.83$ & $0.007 *$ \\
\hline High Fructose Drinks & & $5.83 \pm 4.22$ & $4.38 \pm 2.61$ & $0.038^{*}$ \\
\hline High-magnesium foods & & $6.47 \pm 4.39$ & $6.38 \pm 4.48$ & 0.92 \\
\hline
\end{tabular}




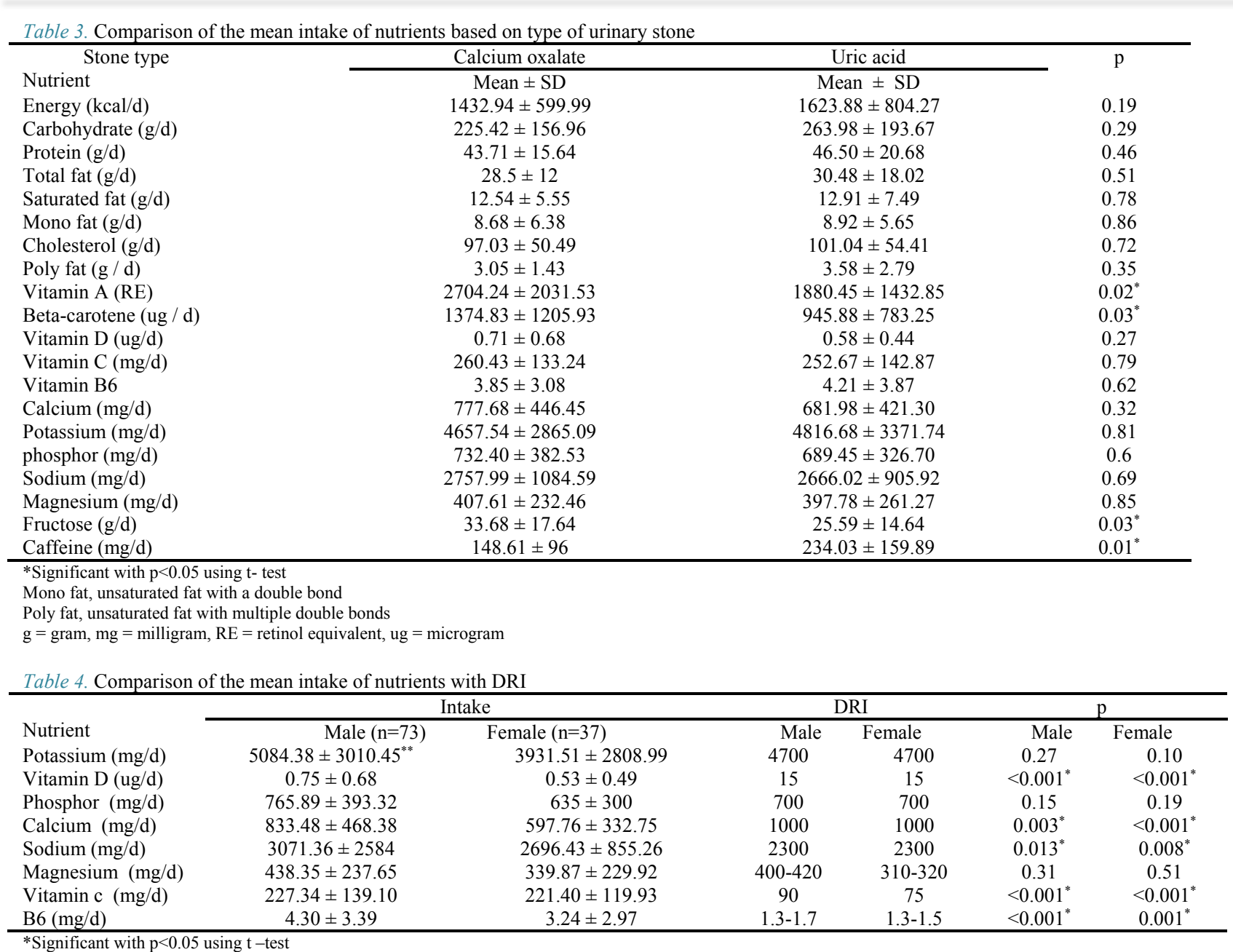

$*$ Significant with $\mathrm{p}<0.05$ using $\mathrm{t}$-test
$* *$ mean $\pm \mathrm{SD}$

in other food groups (Table 5). Also, spontaneous stone expulsion was observed more in participants consuming tap water than in others $(\mathrm{p}=0.81)$ and also in those who consumed strong tea than light tea $(\mathrm{p}=0.63)$ during 1 year, but none were significant (Table 6).

\section{Discussion}

In the past, patients with calcium stones were recommended to limit the intake of high-calcium foods, however, recent studies do not confirm it (24). In the present

Table 5. The relationship between food groups and stone expulsion

\begin{tabular}{lcc}
\hline & Spontaneous stone expulsion duration 1 year \\
Type of food & Correlation coefficient & 0.73 \\
High- potassium fruits & 0.03 & 0.26 \\
High-oxalate foods & -0.1 & $0.005^{*}$ \\
High-oxalate drinks & 0.26 & 0.15 \\
High-calcium foods & -0.13 & 0.10 \\
High- sodium foods & 0.15 & 0.51 \\
High- purine foods & 0.063 & $0.048^{*}$ \\
High- fructose drinks & 0.18 & 0.7 \\
High-magnesium foods & 0.03 & 0.73 \\
Caffeine & -0.033 & \\
\hline
\end{tabular}

*Significant with $\mathrm{p}<0.05$ based on Pearson-coefficient $(\mathrm{p}<0.05)$.

Table 6. The relationship between water and tea consumption with frequency of spontaneous stone expulsion duration 1 year

\begin{tabular}{llc}
\hline Type of drink & & $\begin{array}{c}\text { Frequency of spontaneous stone expulsion duration 1 } \\
\text { year }\end{array}$ \\
\cline { 2 - 3 } Consumed water & Mineral water $(\mathrm{n}=1)$ & Mean \pm standard deviation \\
& Purified water $(\mathrm{n}=1)$ & $2.5 \pm 1.5$ \\
ordinary (Pipe) water $(\mathrm{n}=8)$ & $2.63 \pm 1.36$ \\
Consumed tea & Light tea (n=43) & $2.95 \pm 2.67$ \\
& Heavy tea $(\mathrm{n}=67)$ & $2.72 \pm 2.1$ \\
\hline
\end{tabular}

$\mathrm{P}<0.05$ was considered significant

a. One way Anova, b. Independent $t-$ test 
study, it was found that calcium intake was lower than DRI even in patients with calcium stones. It was also found that the amount of urinary excretion reduced along with an increase in the high-calcium foods intake, but it was not significant, which may be due to the small sample size of the subjects. Similarly, in a case-control study conducted by Leonetti et al, it was found that calcium intake was lower in patients with calcium stones than in healthy participants (25). Considering the importance of calcium for oxalate absorption, decreasing calcium intake may increase urinary oxalate (26). Moreover, it was found that the mean consumption of high-oxalate beverages was significantly higher in patients with calcium oxalate stones than in patients with uric acid stones. Moreover, it is indicated that reducing the intake of high-oxalate foods and 1000 to 1200 milligrams per day calcium from food sources may be a useful approach to reduce the amount of urinary oxalate (27). About $40 \%$ to $50 \%$ of oxalate intake from food is expected to be secreted in urine. However, it is not known whether the amount of oxalate received through diet has a major contribution in stone formation or whether the oxalate in the body plays a significant role. The misinformation about the amount of food oxalate, the bias of the 24-hour food recall and FFQ, different intestinal absorption of oxalate in different individuals, and various availability of oxalate from different food sources may be the reasons behind this, as increased oxalate absorption from oxalate beverages increases the urinary secretion of oxalate (28). Therefore, as the proportion of oxalate formation from internal and food sources is not well understood, In fact, the stone formation cannot be completely attributed to the food intake. According to a study conducted on the effects of diet on urinary oxalate levels, high production of internal oxalate caused high urinary oxalate levels (29).

Consuming animal protein is considered as a risk factor for kidney stones formation. In the present study, it was found that the intake of high-purine foods, such as meat, increases the risk of formation of uric acid stones, more than calcium oxalate stones. This was similar to the results of Tracy et al, who found that consumption of animal protein increases the serum and urinary levels of uric acid in healthy individuals. In addition, fish had a greater impact on uric acid levels due to higher levels of purine compared to beef or chicken (30). It has been indicated that urinary $\mathrm{pH}$ and uric acid decrease due to acidic load by sulfuric amino acids and that the conversion of purine into uric acid results in an increase in urinary level, which increases the risk of stone formation (31).

In this study, it was found that the frequency of stone expulsion during 1 year was higher in patients with an ordinary consumption of water than other groups. Also, stone expulsion was more frequent in those consuming heavy tea than light tea, with a high percentage in black tea and low percentage in green tea consumption. In a study by Brzezicha et al, it was indicated that heavy tea, black tea, and green tea had the highest rate of oxalate stones formation, respectively (32). Therefore, green tea (with low levels of oxalate) is considered as an appropriate choice for patients with kidney stones. Jeong et al in- dicated that green tea, despite its free oxalate content, may prevent stone formation because of the presence of epigalate-catechin (33). Thus, according to the results of these 2 studies, it is suggested that high levels of oxalate in black tea may be a possible mechanism for increasing the number and expulsion of stones. In the present study, it was found that higher consumption of high-oxalate beverages, such as black tea, increased the stone expulsion significantly.

In the present study, the levels of vitamin $\mathrm{C}$ intake was significantly greater in both groups than DRI. A study by Pietro Manuel et al showed no significant relationship between dietary intake of vitamin $\mathrm{C}$ and formation of calcium oxalate stones (34). However, Baxmann et al reported that healthy people who consumed $1 \mathrm{~g}$ of ascorbic acid daily had up to $56 \%$ increased urinary secretion of oxalate and up to $61 \%$ increased stone formation (35). Several studies showed that with a small increase in ascorbic acid intake in men, their risk of stones increased up to $31 \%$ (36). One mechanism of action is that high ascorbic acid levels may convert to oxalate which secreted into the urine due to increased oxidative stress in kidney stones (37).

In the present study, a significant positive correlation was found between the intake of high-fructose beverages and stone expulsion. Taylor et al showed that fructose consumption is independently associated with increased formation of calcium and uric acid stones (21). These results are consistent with the results of our study. Possible mechanisms include using ATP during fructose metabolism, which may result in AMP accumulation. The accumulated AMP is converted into uric acid, which increases its levels (38). Other mechanisms include the role of fructose in insulin resistance and metabolic syndrome (39), both of which are associated with chronic acidosis. Some recent studies indicate that metabolic syndrome is associated with a higher risk of kidney stones (40).

Sodium restriction is a usual recommendation for patients with kidney stones, as high sodium intake is one of the most important factors in stone formation (41). In this study, there was a positive correlation between stone expulsion and high-sodium food, but this difference was not significant. Sodium intake in both groups was greater than DRI in this study. Frassetto et al showed that additional sodium chloride intake may increase metabolic acidosis, leading to bone calcium release and increased urinary secretion of calcium (42). It was found that increased sodium intake reduces calcium reuptake by the kidneys, moves bone calcium, and stimulates the reabsorption of calcium from the intestine, through which the serum calcium levels and urinary secretion of calcium increase (43). It was also showed that increasing sodium intake significantly reduces urinary citrate levels in adults (15), and this may increase the risk of stone formation (47). On the other hand, high sodium intake induces oxidative stress through increasing NADPH oxidase enzyme activity and reducing superoxide dismutase (SOD) enzyme activity (44), which plays an important role in pathogenesis of calcium oxalate stones (45).

Some studies reported that increased levels of active metabolites of vitamin D, such as 1,25 di-hydroxyvitamin 
$\mathrm{D}$, increase calcium secretion (46) and increase the formation of urinary stone. In the present study, it was found that vitamin D intakes from food sources were significantly lower than DRI in patients with kidney stones. In a meta-analysis study, Hai Wang et al showed that serum vitamin D levels were significantly higher in patients with kidney stones than in healthy individuals and that vitamin $\mathrm{D}$ increased the risk of stone formation in these patients (47). In this study, patients who received supplements were not included. However, several other epidemiological studies reported no association between serum 25 hydroxyvitamin D levels and formation of kidney stones and urinary secretion of calcium. Thus, the role of vitamin D supplements in the formation of kidney stones in humans is controversial (48). In this study, the role of sunlight as the main source of vitamin D was not considered and, as the food sources of this vitamin are limited, more attention should be paid to the potential role of this vitamin supplement in the formation of kidney stones. In addition, the dose of vitamin D intake and serum levels of 25 hydroxyvitamin D are also key determinants of kidney stones.

Vitamin A deficiency is considered as a risk factor in the formation of kidney stones (49). In the present study, intake of this vitamin was significantly higher in patients with calcium oxalate stones than those with uric acid stones. Grases et al showed that vitamin A deficiency increased the growth and formation of stones in animals (50). In another study by Nemati et al, it was found that vitamin A intake was higher in patients with uric acid stones than in other patients. The results of their study were not consistent with ours. Since vitamin A mostly exists in animal and dairy foods (51), the high consumption of foods containing this vitamin in patients with calcium oxalate stones may be considered as a possible reason.

Caffeine is another substance whose effect is studied on stone formation. The results of the present study showed that stone expulsion reduced in patients with increasing caffeine intake, but the reduction was not significant, which may be due to the small sample size. Pietro Manuel et al showed that the risk of developing kidney stones decreases with increasing caffeine intake, which is similar to the results of our study. One possible mechanism may be that caffeine prevents calcium and uric acid stones formation by increasing the volume of urine and dilution (52). Thus, caffeine may play a preventive role by impairing ADH hormone in terminal tubules (29).

\section{Conclusion}

Recommendations should focus on reducing the consumption of high oxalate food sources. Furthermore, despite several problems associated with the treatment of kidney stones, patients should be encouraged to improve their dietary habits and reduce their body weight.

\section{Acknowledgments}

This work was financially supported by the Student Research Committee of Shiraz University of Medical Sciences. The authors appreciate the help of Student Re- search Committee of Shiraz University of Medical Sciences and cooperation of managers of Faghihi hospital in Shiraz. The authors also extend their thanks to the personnel and the participants.

\section{Informed consent}

Informed consent was obtained from all participants included in the study.

\section{Study limitations}

The limitations of the study were as follow: Not examining healthy people due to financial limitations; high costs of laboratory tests; and lack of cooperation of patients because the questionnaire was too long to complete (Many patients did not fully complete the questionnaires.).

\section{Conflict of Interests}

The authors declare that they have no competing interests.

\section{References}

1. Johnson CM, Wilson DM, O'Fallon WM, Malek RS, Kurland LT. Renal stone epidemiology: a 25-year study in Rochester, Kidney Int. 1979;16(5):624-31.

2. Corbetta S, Baccarelli A, Aroldi A, Vicentini L, Fogazzi G, EllerVainicher C, et al. Risk factors associated to kidney stones in primary hyperparathyroidism. J Endocrinol Invest. 2005;28(4):122-8.

3. Watanabe T. Proximal renal tubular dysfunction in primary distal renal tubular acidosis. Pediatr. Nephrol. 2005;20(1):86-8.

4. Mandel N, editor Mechanism of stone formation. Semin Nephrol. 1996.

5. Mandel NS, Mandel GS. Urinary tract stone disease in the United States veteran population. II. Geographical analysis of variations in composition. J Urol. 1989;142(6):1516-21.

6. Stamatelou KK, Francis ME, Jones CA, Nyberg LM, Curhan GC. Time trends in reported prevalence of kidney stones in the United States: 1976-1994. Kidney Int. 2003;63(5):1817-23.

7. Tadayyon F, Sabbagh M. The Prevalence of Kidney Stone Different Composition in Patients Referred to the Lithotripsy Wards. J Res Med Sci. 2011;28(122).

8. Blouc, Nigel et al. Stem Cell Urology, Translations by Amir Farrokh Kalhori and Gholam Hossein Hasani, Islamic Azad University, Tehran, Iran, p. 206. [in Persian]

9. Taylor EN, Stampfer MJ, Curhan GC. Obesity, weight gain, and the risk of kidney stones. Jama. 2005;293(4):455-62.

10. Sorensen MD, Kahn AJ, Reiner AP, Tseng TY, Shikany JM, Wallace RB, et al. Impact of nutritional factors on incident kidney stone formation: a report from the WHI OS. J Urol. 2012;187(5):164550

11. Hess B, Michel R, Takkinen R, Ackermann D, Jaeger P. Risk factors for low urinary citrate in calcium nephrolithiasis: low vegetable fibre intake and low urine volume to be added to the list. Nephrol Dial Transplant. 1994;9(6):642-9.

12. Siener R, Schade N, Nicolay C, von UNRUH GE, Hesse A. The efficacy of dietary intervention on urinary risk factors for stone formation in recurrent calcium oxalate stone patients. $J$ Urol. 2005;173(5):1601-5.

13. Siener R, Bade DJ, Hesse A, Hoppe B. Dietary hyperoxaluria is not reduced by treatment with lactic acid bacteria. J Transl Med. 2013;11(1):306.

14. Borghi L, Schianchi T, Meschi T, Guerra A, Allegri F, Maggiore U, et al. Comparison of two diets for the prevention of recurrent stones in idiopathic hypercalciuria. N Engl J Med. 2002;346(2):77-84.

15. Kok DJ, Iestra JA, Doorenbos CJ, Papapoulos SE. The effects of dietary excesses in animal protein and sodium on the composition and the crystallization kinetics of calcium oxalate monohydrate in urines of healthy men. J Clin Endocrinol Metab. 1990;71(4):861-7.

16. Taylor EN, Fung TT, Curhan GC. DASH-style diet associates with reduced risk for kidney stones. J Am Soc Nephrol. 2009;20(10):22539.

17. Taylor EN, Stampfer MJ, Mount DB, Curhan GC. DASH-style diet 
and 24-hour urine composition. Clin J Am Soc Nephrol. 2010;5(12):2315-22.

18. Hu JF, Zhao XH, Parpia B, Campbell TC. Dietary intakes and urinary excretion of calcium and acids: a cross-sectional study of women in China. Am J Clin Nutr. 1993;58(3):398-406.

19. Siener R, Hesse A. Recent advances in nutritional research on urolithiasis. World J Urol. 2005;23(5):304-8.

20. Rodgers A. The influence of South African mineral water on reduction of risk of calcium oxalate kidney stone formation. S Afr Med J. 1998;88(4).

21. Taylor E, Curhan G. Fructose consumption and the risk of kidney stones. Kidney Int. 2008;73(2):207-12.

22. Gh FM. Evaluation of the reliability and validity of Azad-Fesharaki's physical activity questionnaire (AFPAQ). Arak Med Univ J. 2011;14(56):36-44.

23. Hossain Khani A, Nemati A, Naser Saead M, Hosseinzadeh S, Barak M. Relationship between Urolithiasis and Nutrition in Patients with Urinary Stones in Ardabil City. J Ardabil Uni Med Sci. 2012 Nov 15;12(5):65-76

24. Agarwal MM, Singh SK, Mavuduru R, Mandal AK. Preventive fluid and dietary therapy for urolithiasis: An appraisal of strength, controversies and lacunae of current literature. Indian journal of urology: IJU: Indian J Urol. 2011;27(3):310.

25. Leonetti F, Dussol B, Berthezene P, Thirion X, Berland Y. Dietary and urinary risk factors for stones in idiopathic calcium stone formers compared with healthy subjects. Nephrol Dial Transplant. 1998;13(3):617-22.

26. Al Zahrani H, Norman R, Thompson C, Weerasinghe S. The dietary habits of idiopathic calcium stone-formers and normal control subjects. BJU Int. 2000;85(6):616-20.

27. Holmes RP, Knight J, Assimos DG. Lowering urinary oxalate excretion to decrease calcium oxalate stone disease. Urolithiasis. 2016;44(1):27-32

28. von UNRUH GE, Voss S, Sauerbruch T, Hesse A. Reference range for gastrointestinal oxalate absorption measured with a standardized [13 C 2] oxalate absorption test. J Urol. 2003;169(2):687-90.

29. Curhan G. Diet and prevention of kidney stones. Nephrology Rounds. 2004;2(4).

30. Tracy CR, Best S, Bagrodia A, Poindexter JR, Adams-Huet B, Sakhaee K, et al. Animal protein and the risk of kidney stones: a comparative metabolic study of animal protein sources. J Urol. 2014;192(1):137-41.

31. Reddy ST, Wang C-Y, Sakhaee K, Brinkley L, Pak CY. Effect of low-carbohydrate high-protein diets on acid-base balance, stoneforming propensity, and calcium metabolism. Am Kidney Dis. 2002;40(2):265-74.

32. Brzezicha-Cirocka J, Grembecka M, Szefer P. Oxalate, magnesium and calcium content in selected kinds of tea: impact on human health. Eur Food Res Technol. 2016;242(3):383-9.

33. Jeong BC, Kim BS, Kim JI, Kim HH. Effects of green tea on urinary stone formation: an in vivo and in vitro study. J Endourol. 2006;20(5):356-61.

34. Ferraro PM, Curhan GC, Gambaro G, Taylor EN. Total, dietary, and supplemental vitamin $\mathrm{C}$ intake and risk of incident kidney stones. Am J Kidney Dis. 2016;67(3):400-7.

35. Baxmann AC, De OG Mendonca C, Heilberg IP. Effect of vitamin C supplements on urinary oxalate and $\mathrm{pH}$ in calcium stone-forming patients. Kidney Int. 2003;63(3):1066-71.

36. Taylor EN, Stampfer MJ, Curhan GC. Dietary factors and the risk of incident kidney stones in men: new insights after 14 years of followup. J Am Soc Nephrol. 2004;15(12):3225-32.

37. Khan SR. Is oxidative stress, a link between nephrolithiasis and obesity, hypertension, diabetes, chronic kidney disease, metabolic syndrome? Urol Res. 2012;40(2):95-112.

38.Kochman P, Stompór T. Gout, hyperuricemia and chronic kidney disease: New treatment possibilities. Pol Ann Med. 2016;23(2):195201.

39. Kretowicz M, Goszka G, Brymora A, Flisiński M, OdrowążSypniewska G, Manitius J. [Is there a relationship between daily consumption of fructose and blood pressure and uric acid levels in patients with chronic kidney disease without diabetes?]. Nadciśnienie Tętnicze. 2011;15(6):341-346 [in Polish].

40. Elliott SS, Keim NL, Stern JS, Teff K, Havel PJ. Fructose, weight gain, and the insulin resistance syndrome. Am J Clin Nutr. 2002;76(5):911-22.
41. Ticinesi A, Nouvenne A, Maalouf NM, Borghi L, Meschi T. Salt and nephrolithiasis. Nephrol Dial Transplant. 2014;31(1):39-45.

42. Sakhaee K, Harvey JA, Padalino PK, Whitson P, Pak CY. The potential role of salt abuse on the risk for kidney stone formation. $\mathrm{J}$ Urol. 1993;150(2):310-2.

43. Frassetto LA, Morris RC, Sebastian A. Dietary sodium chloride intake independently predicts the degree of hyperchloremic metabolic acidosis in healthy humans consuming a net acid-producing diet. Am J Physiol Renal Physiol. 2007;293(2):F521-F5.

44. Kovacevic L, Wolfe-Christensen C, Edwards L, Sadaps M, Lakshmanan Y. From hypercalciuria to hypocitraturia - a shifting trend in pediatric urolithiasis? J Urol. 2012;188(4):1623-7.

45. Kitiyakara C, Chabrashvili T, Chen Y, Blau J, Karber A, Aslam S, et al. Salt intake, oxidative stress, and renal expression of NADPH oxidase and superoxide dismutase. J Am Soc Nephrol. 2003;14(11):2775-82

46. Khan SR. Reactive oxygen species as the molecular modulators of calcium oxalate kidney stone formation: evidence from clinical and experimental investigations. J Urol. 2013;189(3):803-11.

47. Broadus AE, Insogna KL, Lang R, Ellison AF, Dreyer BE. Evidence for disordered control of 1,25-dihydroxyvitamin $\mathrm{D}$ production in absorptive hypercalciuria. N Engl J Med. 1984;311(2):73-80.

48. Wang H, Man L, Li G, Huang G, Liu N. Association between serum vitamin $\mathrm{D}$ levels and the risk of kidney stone: evidence from a metaanalysis. Nutr J. 2015;15(1):32.

49. Nguyen S, Baggerly L, French C, Heaney RP, Gorham ED, Garland CF. 25-Hydroxyvitamin D in the range of 20 to $100 \mathrm{ng} / \mathrm{mL}$ and incidence of kidney stones. Am J Public Health. 2014;104(9):1783-7.

50. Grases F, Garcia-Gonzalez R, Genestar C, Torres J, March J. Vitamin A and urolithiasis. Clin Chim Acta. 1998;269(2):147-57.

51. Hossain Khani A, Nemati A, Naser Saead M, Hosseinzadeh S, Barak M. Relationship between Urolithiasis and Nutrition in Patients with Urinary Stones in Ardabil City. J Ardabil Uni Med Sci. 2012;12(5):6576.

52. Ferraro PM, Taylor EN, Gambaro G, Curhan GC. Caffeine intake and the risk of kidney stones. Am J Clin Nutr. 2014:ajcn. 089987. 